NOTÍCIA DA EDIÇÃO BRASILEIRA DO BREVE TRATADO DE DEUS, DO HOMEM E DO SEU BEM-ESTAR, DE B. ESPINOSA

Mauricio Rocha...

NOTÍCIAS

INSTRUÇÃO PARA AUTORES.

CONTENTS

\begin{tabular}{c}
\hline \hline A PRESENÇA DE ESPINOSA \\
NAALEMANHA DURANTE O PERÍODO DO \\
NACIONAL-SOCIALISMO: ESPINOSA COMO \\
'CONTRA-EXEMPLO’ DA INFLUÊNCIA DESTRUTIVA \\
DO JUDAÍSMO SOBRE O ESPÍRITO ALEMÃO?’ \\
\hline \hline
\end{tabular}

Manfred Walther ${ }^{* *}$

Enquanto para o completamente não típico alemão Espinosa, a personalidade não possui valor próprio nem liberdade, ela é concebida por Leibniz fundamentalmente como microcosmo. Hermann Glockner (11, p.22)

\section{O "problema-Espinosa"1}

A luta do Nacional-Socialismo [N.S.] pelo revigoramento do povo alemão destinado a dominar o mundo, bem como do espírito alemão, puseram duas tarefas aos intelectuais que figuram entre os - numerosos - seguidores do sistema N.S.: a primeira consiste em evidenciar aqueles poetas e pensadores, mas também os cientistas que figuram na história alemã, nos quais o espírito alemão, não falsificado por influências estranhas, recebeu a sua mais pura expressão. Nesse contexto, Leibniz desempenha, como mostram as contribuições a este volume, um papel central, como o "pensador mais alemão dentre os alemães".

*Tradução de Sérgio Luís Persch, professor da Universidade Federal da Paraíba. ** Professor aposentado da Leibniz Universität Hannover.

**** A versão original do artigo apareceu num volume especial da revista Studia leibnitiana: , 'Leibniz' in der Zeit des Nationalsozialismus“. Hrsg. v. Wenchao Li und Hartmut Rudolph. Stuttgart: Steiner, 2012. 
A outra tarefa igualmente importante consiste em descobrir as influências destrutivas do judaísmo sobre a vida espiritual germânica na Alemanha, na filosofia e na literatura, mas também nas ciências particulares - desde a matemática até as ciências sociais -, com o intuito de poder "eliminá-las" completamente para os tempos futuros. A alegação de que o desmantelamento do povo alemão nos tempos de Weimar tenha ocorrido, sobretudo, "graças" à influência do judaísmo mundial, atuando já há séculos e destruindo o espírito do povo e a substância hereditária dos alemães através do materialismo, do liberalismo, do pensamento legalista, do internacionalismo e do pacifismo, a saber: esse Anti-semitismo de fundamentação racista tem uma grande importância, uma vez que se trata de uma espécie de filosofia da história capaz de tudo esclarecer e emprestar consistência aos elementos heterogêneos da Ideologia N.S.

Agora, dessa conjuntura resulta um grande problema, que coloca em perigo todo aquele empreendimento, a saber, o fato de que Espinosa exerceu uma influência tão gigantesca sobre "poetas e pensadores" genuinamente alemães - desde Lessing, Herder e Goethe, passando por Fichte, até Hölderin, Schelling e Hegel, para nomear apenas os mais importantes - e isso se mantinha quase de todo presente para muitos alemães, principalmente entre os mais cultos. Estavam esses heróis alemães, portanto, igualmente "infestados pelo judaísmo"? Mas o que, então, restava da grande e genuína substância alemã?

No que se segue, apresentarei alguns exemplos de como foi travada essa luta em torno do "problema-Espinosa", e quais resultados produziu. Para tanto, é preciso ter presente de antemão os diversos retratos de Espinosa que foram produzidos no período pós-idealista até 1932. Entretanto, o retrato de Espinosa delineado pelo 'alemão culto' não foi cunhado somente, nem mesmo sequer no que possui de essencial, pela história da filosofia e da ciência, mas - e nisso Espinosa ocupa igualmente uma posição privilegiada - pelos numerosos produtos literários, nos quais Espinosa ora se encontra no centro, ora desempenha um papel importante - desde a poesia de Schiller dedicada a Espinosa, de 1782, até a meia dúzia de romances e dramas sobre Espinosa, que apareceram nas três primeiras décadas do século XX na Alemanha. ${ }^{2}$ Por isso é preciso levar em consideração esses textos literários, principalmente os romances sobre Espinosa, no esboço dos retratos de Espinosa que se difundiram no período anterior ao nacional-socialismo. ${ }^{3}$

\section{Retratos de Espinosa no período anterior a 1933}

Ao longo de todo o século XIX e até 1932, travava-se na Alemanha um debate animado para se saber se Espinosa deveria ser considerado um filósofo judeu. A seguir serão apresentados em ligeiro esboço, e ilustrados através de citações exemplares, alguns retratos de Espinosa que são típicos do período em questão, dos quais resulta claro o quanto foi dura a luta dos ideólogos do N.S. contra o filósofo ‘judeu’ Espinosa.

2.1 Uma vez judeu, sempre judeu

Muitos daqueles filósofos que não têm procedência judaica, os quais se opõem à filosofia de Espinosa não somente de maneira crítica, mas inclusive recusando-o, acentuam que o pensamento dele sem dúvida é tipicamente judeu, apesar da sua excomunhão da comunidade judaica de Amsterdam no ano de 1656, inclusive com o mais severo veredicto de excomunhão que desde sempre fora ali pronunciado. ${ }^{4}$ Tendo por objetivo identificar Espinosa como um pensador judeu e com isso, ao mesmo tempo, desqualificá-lo filosoficamente, Eduard von Hartmann (1842-1906) assevera, por exemplo, de um lado, o caráter total e estritamente formal, que não dá mostras de qualquer conteúdo substancial, da sua filosofia, e do outro lado, remetendo-o a Giordano Bruno, nega-lhe toda originalidade 
relativa ao surgimento do panteísmo moderno (Hartmann 14). Assim ele se mostra como que em duplo sentido irrelevante.

A plausibilidade medíocre da interpretação de Hartmann, em vista da história do impacto de Espinosa na Alemanha, é óbvia. ${ }^{5}$

\subsection{Espinosa, enquanto filósofo, "não mais é judeu"}

Dentre aqueles que apreciam sobremaneira a filosofia de Espinosa, evidencia-se o esforço em livrá-lo de qualquer inspiração judaica.

a) O superintendente geral de Weimar, Johann Gottfried Herder (1744-1803), em virtude da distinção entre o conceito de causalidade imanente, de Espinosa, e a causalidade emanatista da tradição cabalística, entre a linguagem filosófica de Espinosa e a linguagem metafórica da Cabala, que ele estabeleceu em prol da reabilitação de Espinosa em seu livro, promotor da assim chamada Renascença de Espinosa, Gott. Einige Gespräche über Spinoza’s System (Deus. Alguns diálogos acerca do sistema de Espinosa), e tendo em vista o caráter fundamental dessa distinção, logo acrescenta: "Caso contrário, ele teria permanecido um judeu".(Herder 26, p.96).

b) Em seu artigo Die Judenfrage (A questão judaica), o filósofo da esquerda hegeliana, crítico da religião, Bruno Bauer (1809-1881), descreve o trabalho de longos séculos na formação da Europa, para então assinalar: "Não há como citar um único judeu" (Bauer 4, p.49). Porém, imediatamente acrescenta: "Espinosa já não era mais judeu, quando construiu o seu sistema" (Idem ibidem).

c) Também o professor de direito público de Heidelberg e filósofo do direito marcado pelo ressentimento anti-semita (Seen 28 p.372-405), Johann Caspar Bluntschli (1808-1881), no $1^{\circ}$ volume da sua História das ciências na Alemanha, a saber, na Geschichte der neuern Staatswissenschat, Allgemeines Staatsrecht und Politik (História da ciência moderna do
Estado, do direito civil em geral e da política) (Bluntschli 5, p.131), quando se refere à exclusão de Espinosa da comunidade de Amsterdam, afirma imediatamente a seguir: "Ele não era mais judeu", para então expor com muita perspicácia o que há de específico no pensamento de Espinosa acerca do Direito.

Ao longo de todo o século XIX, é essa postura que muitos assumem, na medida em que têm um apreço especial por Espinosa e, ao mesmo tempo, combatem o 'judaísmo'.

d) A esse contexto dos esforços em apresentar Espinosa, com base em sua importância acentuada para a filosofia e a literatura do período clássico, como um pensador que teria se emancipado inteiramente da sua procedência judaica, pertencem também dois romances sobre Espinosa, escritos no começo do século XX.

- O escritor de orientação anti-semita Otto Hauser (1875-1944), de Österreich, após interromper os seus estudos das línguas orientais e da teologia evangélica, publicou em 1907 a obra Spinoza. Roman (Hauser 15), na qual desenvolve a "dupla oposição frontal de Espinosa, de um lado, ao judaísmo mundano-comercial (contra o judaísmo do seu pai) e, do outro, ao judaísmo da fidelidade à religião e à lei (contra o judaísmo da comunidade)" (Kilcher 20, p.87).

- Apenas um ano depois, aparece Amor Dei. Ein SpinozaRoman (Amor Dei. Um romance sobre Espinosa), do alemão-húngaro Erwin Guido Kolbenheyer (1878-1962) (Kolbenheyer 21), o qual dispõe de conhecimentos muito mais detalhados que os de Hauser acerca da comunidade holandesa do tempo de Spinoza e das pesquisas biográficas acerca de Espinosa. ${ }^{6}$ Enquanto estudioso zoólogo, psicólogo e filósofo (Dr. Fil., Viena 1905), ele acentua, com uma tendência básica similar à de Hauser, a "condicionalidade do Eu afetada por impulsos" (triebhafte Ich-Bedingtheit) da vida humana e faz Espinosa descobrir Giordano 
Bruno e, abandonando a tradição judaica, entrar no círculo de van den Ende. Kolbenheyer descreve Espinosa, ao lado do artista (Rembrandt) e do homem de ação (Jan de Witt), como um desses homens que vivem plenamente o seu amor fati. No entanto, Espinosa excede os dois outros, na medida em que, "affranchi de la servitude de la foule comme de la tyrannie", ele formula enquanto filósofo, isto é, enquanto "spectateur froid et lucide de la destinée politique", as leis do "antagonisme irréductible entre la foule, la masse, la populance, l'humanité médiocre” de um lado e, do outro, as do "individu du génie" (Lagny 22, p.480-481).

2.3 Espinosa como pensador que supera todas as estruturas nacionalistas: o (primeiro) universalista

A discussão alcança um nível totalmente distinto, assim que a emancipação de Spinoza, da sua procedência e do universo do pensamento judaico, passa a ser vista como exemplar para aquela tarefa com a qual se depara a Europa no contexto da modernidade. O dado biográfico que serve como ponto de partida para tal é o fato de que Espinosa, após ter sido banido da comunidade judaica, não ter se filiado a nenhuma outra religião positiva ou denominação religiosa.

a) A perspectiva trazida à tona pela Aufklärung, de que os homens, sem prejuízo para as suas respectivas procedências, poderiam chegar a um acordo mútuo em prol de uma coexistência duradoura e pacífica, seguindo uma orientação universalista baseada na ideia de uma verdade única, influencia o traçado do retrato de Espinosa após o término da filosofia idealista, sobretudo, em primeiro lugar, no contexto judaico. Essa perspectiva parece bastante promissora para o futuro, sobretudo porque não promete apenas uma emancipação dos judeus da sua existência fechada em gueto, mas porque se concebe, ao mesmo tempo e na mesma medida, como pós-cristã. Somente depois de rompido o poder das ortodoxias de todas as tradições é que a emancipação particular dos judeus poderá se estender à humanidade toda. $\mathrm{O}$ que se oferece, mais nessa perspectiva enquanto ponto de orientação do que no exemplo propriamente dito de Espinosa, que se emancipou da sua procedência judaica, não como um cristão, mas sim, de toda a positividade religiosa?

Essa perspectiva conhece um primeiro retrato impressionante e, devido à grande disseminação da obra, eficiente, no romance $\operatorname{Spinoza}^{7}$ de Moses Baruch, mais tarde Berthold Auerbach (1812-1882), que também traduziu para o alemão e publicou uma edição em vários volumes das obras de Espinosa e se tornaria conhecido de um público leitor ainda mais vasto com os seus Contos de aldeia. Após o relato das lutas internas e externas que Spinoza teve que travar em seu processo de maturação supostamente precoce, Auerbach conclui: "Baruch já não era o filho de Israel, ele era o filho da Humanidade"(Auerbach 2, p.101). E, numa conversa fictícia de L. Meyer com o herói, Auerbach também confere ao caso uma explicação, por assim dizer, sociológico-científica, de que tenha sido aquele um judeu que se tornou o primeiro filho da humanidade. Nessa conversa, Meyer diz o seguinte:

"Ojudeu que, além do mais, libertou-se da sua própria tradição dilacerada, é o estrangeiro propriamente desembaraçado no mundo, provido de todas as armas do espírito humano; não obstante, examinar e compreender o mundo todo, tal como é dado na história, com um olho intacto de criança, eis uma vantagem e uma liberdade que ninguém outro há de alcançar facilmente". (Auerbach 3, p.230)

Essa é, decerto, a formulação mais concisa disso que os protagonistas da consciência emancipatória judaica tomam por evidente no século XIX. 
b) Tão plausível quanto seja essa interpretação de Espinosa no contexto do esforço que fizeram os intelectuais judeus para se colocar al pari do que há (segundo a opinião deles) de mais avançado na cultura, na filosofia e na ciência modernas, tão surpreendente vem a ser que essa mesma interpretação se encontre também num filósofo alemão do século XX, que se propusera justamente a tarefa de provar que as marcas características das diversas filosofias, na Europa, devem-se aos respectivos espíritos nacionalistas. O habilitado fisiólogo (Heidelberg, 1857) e, posteriormente, filósofo e psicólogo Wilhelm Wundt (1832-1920), em sua monografia Die Nationen und ihre Philosophie. Ein Kapitel zum Weltkrieg (As nações e suas filosofias. Um pretexto para a guerra mundial) (Wundt 39$)^{8}$, relativamente à influência de Descartes, diz o seguinte:

"Eis que se mostra muito significativo, para as ações recíprocas dos povos que tomam parte na cultura dessa época, o fato de que o homem que resolveu o problema colocado pelo filósofo francês, não de maneira definitiva [...], mas conforme o espírito do tempo e de acordo com a situação que apresentam os pressupostos assumidos nas ciências, não pertence a nação alguma, ou, melhor dizendo, pertence simultaneamente aos povos diversos que, naquele tempo, tomavam parte no trabalho espiritual. Esse homem é Espinosa [...]. Uma vez que Espinosa pertenceu, de nascimento, àquele ramo do povo judeu que, por sua formação e inteligência, transpôs largamente os limites do judaísmo oriental, e depois, em terreno holandês, foi influenciado pela cultura germânica presente na nação que o abrigou, e, por intermédio das relações internacionais, travou contato com a ciência italiana, francesa e alemã [surpreendentemente o contexto inglês não é referido, M. W.], a sua filosofia é, num sentido bastante próprio, inter-nacional [...]. Se ali, nesse contexto de pensamentos que vieram amadurecendo durante um período prévio nas mais diferentes nações da Europa, originou-se uma visão de mundo que, por conferir uma unidade a todos esses elementos, talvez seja a expressão mais perfeita da complexidade de pensamentos daquela época, todavia, ela não foi capaz de se reconhecer nesse sistema". (Wundt 39, p.25-27, os itálicos não estão no original).

2.4 A (meia) incorporação de Espinosa no circuito cultural alemão

No ano de 1890 aparece um escrito, no qual o autor exorta os alemães para que, em consideração retrospectiva da peculiaridade dos alemães enquanto o povo dos individualistas e como recusa do mecanicismo e do materialismo, retornem novamente para aquela unidade da cultura artística e filosófica, que veio quase a sucumbir, especialmente sob a influência destrutiva dos judeus. O autor, Julius Langbehn (1851-1907) alegava que, para tanto, um papel central cabia especialmente à cultura da baixa Alemanha - incluindo-se os holandeses - e que o pintor Rembrandt, o qual, "dentre todos os artistas alemães, é, porém, [...] o mais individualista", ou ainda, "o mais alemão de todos os artistas alemães", poderia e deveria servir como um "protótipo do gênio alemão" e, assim, como "figura exemplar do renascimento nacionalista" (Schewe 25, p.1084) - o que rendeu ao autor o apelido de 'Rembrandt Alemão'. Trata-se do Rembrandt als Erzieher (Rembrandt como educador) de Julius Langbehns (23), do qual, somente nos primeiros dois anos, foram impressos 39.000 exemplares. Nesse 'escrito para um despertar', Espinosa também não desempenha um papel insignificante, o que não admira, por causa do que se considera acerca da contribuição do pensamento dele para o ápice da cultura alemã. Langbehn toma como ponto de partida o fato de que Rembrandt e Espinosa viviam ao mesmo tempo e pouco distantes um do outro no quartel judeu de Amsterdã. Ele vê, para o seu projeto, outras várias semelhanças significativas entre ambos. Por isso, dedica uma alínea do seu livro à "Relação [de Rembrandt] com Espinosa" (Langbehn 23, p.48-50). ${ }^{9}$ 
"Nesse sentido [a saber, com referência ao fato de que Rembrandt trouxera tudo 'numa relação direta com o mundo, o homem, o coração'], ele é tocado, de modo bastante peculiar, pelo seu grande companheiro do tempo, de nação e inclusive de procedência, Espinosa; neste se condensa em uma personalidade singular pura o judaísmo originariamente aristocrático ${ }^{10}$ que Rembrandt destaca tão diversamente em sua arte" (Langbehn 23, p.50).

É verdade que, logo em seguida, lemos: "O judeu oferece a sabedoria do além-mundo, e o alemão, a sabedoria do cotidiano; e por isso, a sabedoria melhor, a mais acessível e mais aprazível" (Langbehn 23, p.51). Após indicar que ali houve "uma influência mútua frutífera de dois domínios distantes e aparentemente opostos um ao outro", segue, sob a expressão capitular de "ação recíproca", enquanto uma expressão que designa "um conceito bem especificamente alemão", a alusão ao fato de que,

“(em) meio à arte culta [...], uma relação semelhante, que dois homens significativos mantêm entre si, encontrou a sua melhor e, poderia dizer-se, mais insuperável expressão através do duplo retrato de Schiller e Goethe em Weimar, de Rietschel [em frente ao Teatro Nacional]. Poeta e pensador, que ali se transmutam ambos um sobre o outro, sustentam conjuntamente uma coroa de honra" (Langbehn 23).

E o autor continua: "Da mesma forma, Rembrandt e Espinosa, em que o poeta e o pensador se transmutam um sobre o outro de maneira ainda mais abrangente do que aqueles, sustentam também conjuntamente uma coroa de honra; chama-se: liberdade holandesa" (Langbehn 23, p.50).

E mais para o final do livro, ainda consta isto:

"Essa dupla face [de claro e escuro] se encontra mais conjunta ainda especialmente no domínio espiritual; Espinosa, o filósofo esclarecido, e Rembrandt, o pintor obscuro, mostram-se aqui novamente como o par gêmeo hostil, tais como foram reconhecidos acima. Espinosa, esse solitário polidor de lentes, no interior do seu pequeno quartinho de pensão, daria para Rembrandt o mais preciso objeto para uma gravura; esse último experimenta, no período após a sua falência, os efeitos penosos dela com uma calma e resignação filosófica, que teriam sido plenamente dignos do primeiro. Luz e sombra preenchem a ambos tanto interna quanto externamente; luz e sombra os sobrepõe um ao outro. Eles formam um par claro-escuro. Espinosa tem algo da inflexibilidade alemã em seu modo de pensar, e Rembrandt, algo da flexibilidade oriental em sua arte; cada um deles é tão significativo porque lhes foi possível, enquanto pessoa, compreender em si próprio alguma coisa que se opunha à sua raça e, dessa forma, fertilizá-las. Uma coisa somente se eleva à sua perfeição quando se transforma no oposto de si mesma; trata-se de uma sabedoria em lusco-fusco, mas é justamente no lusco-fusco que se pensa melhor." (Langbehn 23, p.272; os itálicos não constam no original).

Foi assim que Espinosa, ao lado e em contraposição a Rembrandt, apesar da sua proveniência oriental, acabou sendo introduzido de alguma forma no circuito da cultura alemã.

Quando Alfred Wenzel (1865-?) escreve, no $1^{\circ}$ (e único) volume da sua monografia sobre Espinosa, de 1907, que, enquanto judeu, Espinosa justamente "trouxe a vida espiritual da raça germânica à mais perfeita florescência" (Wenzel 36, p.33), isso soa como um reflexo - mais uma vez aumentado - do duplo retrato de Langbehn.

Quanto às dissonâncias cognitivas e afetivas que esses retratos de Espinosa assaz diversos são capazes de produzir, inclusive nos homens que se encontram próximos do Nacional-Socialismo, seja mencionado aqui apenas isso que tem a dizer acerca de Espinosa, em 1932, o então Oficial 
da Marinha e Comandante do Corpo de Voluntários. Tendo terminado seu doutorado em 1923, o escritor Bogislav von Selchow (1877-1943), o qual então se tornaria membro da Academia do Direito Alemão fundada pelo Nacional-Socialismo no 'Terceiro Reich', afirma o seguinte:

“A doutrina de Espinosa não é tão significativa pelo fato de que o curso de seus pensamentos o conduzem, ele o solitário e incompreendido, muito para além da consciência do seu tempo, mas sim, pelo fato de que o conflito originário de toda a filosofia recebeu com ele a mais clara expressão, o conflito entre o impulso humano do pensamento, dirigido à derradeira unidade, e a matéria que se lhe opõe [...] Não restam dúvidas de que Espinosa falha [...] E mesmo assim há que se continuar admirando em Espinosa a maneira como a vontade desatenta do pensamento sempre se dobra de novo ante um sentido forte da realidade (Selchow 27, seção sobre Espinosa, p.224-232)

Na medida em que concebe o surgimento do Estado "a partir de energias impulsivas elementares, ele recupera ideias que, na Filosofia do Direito, foram relegadas ao esquecimento desde os tempos da Alta Escolástica..." (Selchow 27, seção sobre Espinosa, p.224-232). Isso, não obstante as complexas influências que ligam Espinosa com o Renascimento e o Humanismo, com Descartes e Hobbes:

"Se ele permanece solitário e estranho e incompreendido entre os seus contemporâneos, fundamentalmente isso se deve menos à grandeza e à fertilidade dos seus pensamentos para o futuro, do que à espiritualidade de constituição inteiramente diversa, pela qual não se pode negar a sua proveniência do Gueto. A sutileza talmúdica, o fio condutor do pensamento afiado como uma faca, o predomínio do formal, o caráter abstrato gelidamente estranho, tudo isso o liga ao modo de pensar judeu [...]. A mais profunda fé na vida, a confiança absolutamente inesgotável na realidade divina de todo ser e, ao lado disso, dura e estranhamente, uma objetividade destituída de ilusões, tudo isso, em última instância, só pode ser esclarecido da constituição do espírito tipicamente semita".

Entretanto, imediatamente a seguir consta mais uma vez: "Em Espinosa, que nunca deixou de afirmar a felicidade da alma nas mais críticas circunstâncias, uma parcela, a mais nobre do judaísmo, ganhou forma simbólica". (Selchow 27, seção sobre Espinosa, p.224-232).

Esse texto de 1932 articula de modo particular expressões típicas da polêmica caracterização do pensamento "judaico" com acentuada fertilidade do pensamento de Espinosa para o futuro, inclusive com surpreendente reconhecimento. É evidente o dilema em que se encontra o autor no que diz respeito à contribuição do pensamento de Spinoza.

\section{A presença de Espinosa no período NS}

O interesse por Spinoza também é intenso durante o 'Terceiro Reich': o Rembrandt como educador de Langbehn, que somente nos dois primeiros anos foi publicado em 39.000 exemplares - a partir da $13^{\mathrm{a}}$ edição, de 1890 , numa versão bem mais ampliada, a partir da $37^{\mathrm{a}}$ edição, de 1891 , com numerosas inserções e mudanças - teve a sua publicação renovada em 1934, 1935, 1936 e, como 85ª -90 tiragem (nova edição) foi novamente publicada em 1943, em certa medida como edição popular. O leitor pode ler nela sobre o "parentesco de almas" entre Espinosa e Rembrandt, o "mais alemão de todos os artistas alemães", algo comparável com o par de gênios personificado na Estátua Schiller-Goethe de Weimar, e sobre o fato de que Espinosa possui alguma coisa "da inflexibilidade alemã". ${ }^{11}$ 
O Spinoza-Roman de Kolbenheyer foi republicado em 25.000 exemplares entre 1933 e 1943, ainda que Kolbenheyer, tanto pelas suas publicações e atividades, quanto pelas distinções que obtém no período $\mathrm{NS},{ }^{12}$ seja um autor 'insuspeito', para quem Espinosa é diretamente paradigmático à emancipação radical do judaísmo.

E o escrito de Wilhelm Wundt, Über die Nationen und ihre Philosophie (Sobre as nações e sua filosofia), que havia aparecido em oito edições antes de 1933, é assistida com mais edições em 1935, 1941 e 1944, dentre as quais a última ainda mantém a glorificação de Espinosa, citada acima, de maneira totalmente inalterada (cf. Wundt 40, p.25-27).

O grande interesse por Espinosa, cuja larga existência é atestada por essas indicações, esclarece também o que à primeira vista surpreende:

A obra principal de Spinoza, a Ética, deve ter sido editada de novo, tanto em 1939 na edição de Kröner, quanto também na edição da Reclam, aqui obviamente sem que o tradutor Jakob Stern tenha sido avisado, ainda que, obviamente, não tenham aparecido nas vitrines das livrarias.

E o volume de Kuno Fischer sobre Espinosa, da sua grande Geschichte der neuern Philosophie (História da filosofia moderna), uma das mais editadas monografias em língua alemã sobre Spinoza, que cunhou o retrato de Espinosa para várias gerações, foi "liberada para "venda sem propaganda", na reedição de Carl Gebhardt, por meio do $1^{\circ}$ Ofício de Aprovação da Câmara da Literatura do Reich, de 27.1.1944(!) "em caráter excepcional, devido ao seu [do livro] caráter rigorosamente científico" - que naturalmente se faria acompanhar da edição, "desde que vos seja possível suprimir algumas passagens que contêm uma tendência pró-judaica excessivamente acentuada, como principalmente a página 109". ${ }^{13}$ A editora universitária Carl Winter, em Heidelberg, não se vê na possibilidade de cobrir com tinta preta essa passagem na folha já impressa e, com isso, renuncia à publicação de uma versão censurada, e o volume aparece logo após o fim do 'Terceiro Reich', em 1946.

Além do mais, aparecem vários escritos acadêmicos sobre Espinosa, que são publicados mediante as condições de censura, e apresentam da mesma forma um retrato bastante positivo de Espinosa. Sejam apresentados com mais pormenores, três exemplos.

a) Como primeiro exemplo, há que se referir à monografia sobre Espinosa, em quatro volumes, do Jesuíta Stanislaus von Dunin-Borkowski (1864-1934), cujos volumes apareceram em separado entre 1933 e 1936 - um dos livros mais abrangentes sobre Espinosa, que jamais foram publicados (Dunin-Borkowski 7). Uma vez que Dunin-Borkowski, que dispõe de um conhecimento impressionante, toma uma postura assaz crítica frente a Espinosa e, além disso, encontra-se sob a proteção da Igreja Católica, praticamente não há motivo algum para impedir a publicação.

Ao lado deste, há uma série de livros cujos autores são protestantes e que não permitem qualquer delator de inimizade a Espinosa. Dois deles sejam apresentados com mais precisão.

b) No ano de 1937, portanto, no quinto ano do domínio NS, aparece uma monografia sobre Deutsche Klassik und Reformation (O Classicismo alemão e Reforma), de Erich Franz (Franz 9), a qual obtivera o prêmio da Academia Prussiana das Ciências em 1935. O prefácio - que os censores liam com constância e cuidado - salienta que

"as maiores criações espirituais [...] na verdade também (surgem), em todo caso, de condições raciais e culturais determinadas [...], mas segundo a sua pretensão de validade e a história dos seus efeitos, elas vão muito além da esfera limitada da sua pátria” (Franz 9, p. IX).

Porém, na mesma página se constata, em seguida, 
"que os poetas e pensadores se elevam gradualmente do concreto, das satisfações vitais (sic!) do povo e da particularidade inerente à sua proveniência, em direção aos ideais universais da 'humanidade', do cosmopolitismo" (Franz 9, p.IX-X).

Poucas páginas adiante, porém, consta de novo:

"O idealismo alemão é a tentativa, levada a cabo mediante a convocação de gigantescas energias do espírito e do ânimo, de compreender conjuntamente em uma nova e grande síntese, a experiência dos valores destroçados, e harmonizar o conteúdo mais profundo da tradição religiosa com a liberdade e maioridade do homem moderno" (Franz 9, p. X)

Podemos notar: O Prefácio está cheio de contradições que mal podem passar despercebidas e, dessa forma, consiste num exemplo típico daquilo que Leo Strauss, sob o tema Persecution and the Art of Writing, estabeleceu como máxima hermenêutica da sua interpretação do Tratado teológico-político de Spinoza (Strauss 30). Essas contradições são inteiramente conscientes ao leitor contemporâneo, e ele entende o que o autor quer partilhar dessa maneira.

Sobre esse pano de fundo, também não surpreende que na parte do texto principal acerca da significação acentuada do movimento em torno de Espinosa, com inclusão de Lessing, Goethe e Herder, é dedicada à cultura alemã (Strauss 30, p.403-407), não há nenhum indício de que o autor se distancia dessa elevada valorização de Espinosa pelos clássicos.

c) O terceiro exemplo é um livro de Hans Hölters, que se ocupa igualmente com a assim chamada Renascença de Espinosa em torno de 1800: Der spinozistische Gottesbegriff bei M. Mendelssohn und F. H. Jacobi und der Gottesbegriff bei Spinoza (O conceito espinosista de Deus em M. Mendelssohn e F. H. Jacobi e o conceito de Deus em Espinosa), o qual aparece um ano após o trabalho de Franz (Hölters 18). Num prefácio, o editor da série, Siegfried Behn, pergunta: “[...] será que Espinosa, na sua forma peculiar, não permaneceu muito mais distante da vida espiritual alemã, ele não teve que ser mal compreendido para aparentemente ser apropriado?" (Hölters 18, não pag.). E ele percebe como sendo a essência da pesquisa de Hölters, ter ele contribuído para provar que "a intenção doutrinária particular de Espinosa [...] é totalmente distinta do 'espinosismo' alemão" (Hölters 18, prefácio, não pag.). Isso serve para aquietar os censores. Se nos voltarmos para o próprio trabalho de Hölters, de fato, descobrimos que o autor critica tanto Mendelsohn quanto também Jacobi, por terem compreendido mal a doutrina de Espinosa acerca dos modos de Deus, mas procuraremos em vão expressões anti-semitas na parte que trata do judeu Mendelssohn, e quando o autor explica a verdadeira doutrina de Espinosa acerca de Deus, não se encontra nenhuma referência a um possível distanciamento que Hölters toma com relação a essa doutrina. Na última frase, Hölters diz que ele pretende, com seu livro, contribuir para "o sentido eterno de filosofia”, a saber, “ao amor pela verdade” ((Hölters 18, p.89).

Há, portanto, - assim é possível sintetizar o resultado - também durante o período NS, a possibilidade de realizar pesquisas sólidas sobre Espinosa e salientar o seu significado para a cultura alemã - naturalmente, pagando-se o preço de abrir mão de quaisquer artigos de fé, os quais, porém, nada têm a ver de distintivo com relação àquilo que o autor tem a dizer acerca de Espinosa.

Podemos notar: Espinosa está tão naturalizado na cultura alemã, que a censura, até mesmo no período NS, não ousou proibi-lo completamente, e que a pesquisa relacionada a temáticas de Espinosa podia ser realizada sem ressentimento anti-semita também na sombra da censura. Essa é a tarefa 
de identificá-lo como um pensador judeu e, assim, excluí-lo do discurso que o faz objeto de luta em torno da reconquista do genuíno germanismo, uma vez que ali há uma série desses autores, cujos retratos de Espinosa foram referidos na $2^{\mathrm{a}}$ parte, que devem inequivocamente ser remetidos ao armazém 'popular'.

\section{Uma tentativa de indicar o caráter judaico da doutrina de Espinosa}

O quão aferrada está a consciência do "problema-Espinosa" em vista do seu significado para o período clássico da filosofia e da poesia alemãs, para os cultos dentre os protagonistas ativos do Nacionalsocialismo, é perceptível no seguinte detalhe:

No ano de 1936, o Grupo do Reich chamado Escolas Superiores da Aliança do Direito Autêntico, sob a direção do Professor de Direito Público Carl Schmitt, promoveu uma Jornada sobre "O Judaísmo na Ciência do Direito", na qual se seguiu o rastro da influência funesta do judaísmo em todas as partes do domínio da dogmática do direito alemão. Na "entrevista" que acompanhava as conferências da jornada, também fez uso da palavra o "Dirigente de Comarca, o Procurador do Direito, Schroer" e fez exposições mais prolongadas sobre "A relação dos judeus com a lei" ${ }^{14} \mathrm{Na}$ conclusão de sua conferência, Schroer passou a falar da "atitude filosófica da seleta comunidade culta no século XIX" (Schroer 26, p.21-22), especialmente do "humanismo" no qual se funda o "filosemitismo". "O humanismo está estreitamente relacionado com a história do espírito judeu”. Após algumas observações sobre o "amigo dos judeus" do século XVI, Johannes Reuchlin, ele passa, sem que ainda subsistisse uma conexão com o tema da jornada, "Ciência do Direito", a falar de Goethe, e diz dele o seguinte:

"É possível provar que, no humanismo tardio do tempo de Goethe, o espírito judeu, na figura de Espinosa, influenciou decisivamente a vida espiritual do humanismo. Goethe, que reconhecidamente recusava o judaísmo, todavia não se livrou do veneno insidioso do modo de pensar judaico, que influenciava o universo do humanismo enquanto espinosismo, e com o qual Goethe" - ainda assim - "teve que lutar durante toda a sua vida. Judeus alegaram que Goethe teria sofrido de uma doença da alma e que teria encontrado a paz somente nos braços espirituosos de Espinosa. ${ }^{15}$ Porém, conforme nos é garantido, Espinosa não é pensável sem o Talmude" (Schroer 26, p.21-22).

Ainda que o assunto propriamente dito se refira ao pensamento judaico em torno da lei, foi preciso que Schroer, no final das contas, chegasse a falar do "problema-Espinosa", como algo que motivou a "comunidade culta" - e não somente, como ele bem sabe (veja o que foi tratado na segunda parte), "no século XIX".

Agora bem, como se apresentam as tentativas, apesar dos retratos de Spinoza esboçados por Hauser, Kolbenheyer e Wundt, de apontar o caráter demasiadamente judaico da filosofia de Spinoza e, dessa forma, 'eliminá-la' definitivamente da história do pensamento alemão?

Eu seleciono três exemplos.

4.1 O filósofo e psicólogo de Munique, Hans Alfred Grunsky (1902-1988) (Grunsky 13), filiado desde 1930 e, a partir de 1935, docente titular de filosofia do "Departamento de Política Cultural e Política de Vigilância" ("Instituto Rosenberg"), entende o sistema de Espinosa, baseando-se na falta de conexão dos atributos infinitos, apesar da alegação abstrata de sua unidade, ${ }^{16}$ como uma compreensão nova e revolucionária do espírito talmúdico do judaísmo. Esse espírito permite a Espinosa, numa genuína demagogia rabínica, a partir da indicação de relações meramente formais entre os elementos particulares desconexos da realidade, conjuntar 
o instinto vital desenfreado com o afeto intelectual do estudo do Talmude de maneira tal que a "coesão da lei mosaica" (Grunsky 13, p.112), que é capaz de isolar os judeus no mundo moderno, transcenda para uma lei universal da igualdade de todos os homens. Dessa forma, Espinosa não faz um trabalho de assimilação dele próprio e da tradição judaica aos nãojudeus, mas pelo contrário, ds não-judeus aos judeus (cf. Grunsky 13, p.113). O fato de a filosofia alemã se mostrar tão fortemente influenciada por Espinosa deve-se a ele ter sido o primeiro a empreender a síntese, que começava a aflorar na história do pensamento, entre a ciência natural e a mística, e que seria a grande tarefa colocada para o pensamento ariano, mas ele a empreendeu antes do tempo e, portanto, de maneira prematura. Foi justamente isso que impressionou o pensamento ariano, de modo que "a invasão de Espinosa na filosofia germânica se seguiu a um momento em que esta se encontrava numa grande e ainda não resolvida crise de desenvolvimento". Mas apesar disso, "o retrato pode ser subjugado por uma recusa instintiva(!)", desde que "se combinem os juízos verdadeiros de nossos pensadores alemães sobre Espinosa, e não os juízos retocados e falsificados pelo judaísmo": ali se encontra, pois, uma frente, "que começa em Leibniz, passa por Kant e chega até Hegel, Schopenhauer e Nietzsche" (Grunsky 13, p.115). ${ }^{17}$

Que Espinosa "seja o primeiro" a empreender uma tarefa, cuja solução será realmente obtida (somente) "com o pensamento ariano" essa é uma resposta muito ambígua ao "problema-Espinosa"!

4.2 Aquilo que Grunsky ainda procurava esboçar por meio de argumentos se transforma, então, com o filósofo e decano temporário da faculdade filosófica de Giess, Hermann Glockner (1896-1979), em sua monografia Vom Wesen deutscher Philosophie (Sobre a essência da filosofia alemã) (Glockner 11, p.22), nestas observações lapidares: "Sobre o terreno não alemão do espinosismo, a formação dessa doutrina da liberdade [i.e. da alemã] teria sido impossível. O judeu Espinosa é o mais significativo adversário e rival da filosofia alemã [...] Com o autêntico Espinosa, jamais alemão algum soube iniciar qualquer coisa; se bem que ainda, de vez em quando, a compaixão por esse homem, abandonado por seu povo e sua pátria, ajudava a pintar um retrato falso, ajustado ao sentimento alemão" (Glockner 11, p.23).

Maior "calúnia", para exprimi-lo na terminologia corrente daquele tempo, mal podia ser perpetrada contra os heróis do autêntico germanismo, do que mostrar que a grande estima em que tinham Espinosa era condicionada apenas por um afeto, o da compaixão.

4.3 Um dos ideólogos chefes do Nacional-Socialismo, o propagandista do Nacional-Socialismo Alfred Rosenberg (1843-1964), e seu escrito combativo Die Spur des Juden im Wandel der Zeiten (O rastro do judeu no decorrer dos tempos), ${ }^{18}$ que foi editado pela primeira vez já em 1920 e foi três vezes reeditado no período NS, por último em 1943, fala acerca do tema o seguinte: "Mas a partir de Jowett, já não há mais dúvida de que Espinosa deve todos os seus efetivos pensamentos ao espírito de dois homens: Descartes e Giordano Bruno" (Rosenberg 24, p.130).

Se fosse assim - que Bruno seja o criador autêntico do panteísmo que se atribui falsamente a Espinosa, Rosenberg já podia ter lido em Eduard von Hartmann e no Amor Dei de Kolbenheyer, obra que foi antecedida por um romance sobre Bruno, do mesmo autor -, então esse argumento seria devastador para o que Rosenberg pretendia demonstrar, e num duplo sentido: de um lado, os grandes pensadores alemães após Kant teriam recolhido então apenas um epígono rotulado e, do outro, a filosofia de Espinosa, pelo menos em sua parte mais significativa, não teria nada a ver com o judaísmo!

Resultado: As tentativas de mostrar Espinosa como um corpo 
estranho,judaico-destrutivo, na história da autêntica cultura alemã mostramse singularmente desamparadas ou, no mínimo, discordantes. Elas não são capazes de oferecer ao "problema-Espinosa" uma solução construída de modo argumentativo e que, de antemão, já não estejam convencidas do resultado que pretendia alcançar.

Entretanto, no período que se segue ao fim da $2^{\text {a }}$ Guerra Mundial, essa estratégia de exclusão teve certo 'êxito' tardio, quando, pelo menos na Alemanha Ocidental, demorou mais de $20 \operatorname{anos}^{19}$ até que Espinosa voltasse a ser objeto de trabalho filosófico monográfico - e nessa retomada desempenharam um papel importante e estimularam novos interessados, sobretudo, aqueles professores acadêmicos que haviam sido academicamente socializados ainda no tempo de Weimar.

\section{REFERÊNCIAS BIBLIOGRÁFICAS}

1. AUERBACH, B. Ein historischer Roman. (Espinosa. Um romance histórico). Stuttgart: Scheible, 1837.

2. _. Spinoza. Ein Denkerleben, (Espinosa. Uma vida de pensador), $1^{\circ}$ vol. Stuttgart; Augsburg, 1858 (Obras completas de Berthold Auerbach, primeira edição completa, 10).

3. Spinoza. Ein Denkerleben. Com uma introdução de Anton Bettelheim. Leipzig, Hesse \& Becker, sem data. [1913]

4. BAUER, B. Die Judenfrage (A questão judaica), Deutsche Jahrbücher Nr. 274 (1842).

5. BLUNTSCHLI, J. G. Geschichte der neuern Staatswissenschat, Allgemeines Staatsrecht und Politik (História da ciência moderna do Estado, do direito civil em geral e da política), München u. a.: Oldenbourg, 1881 (Repr. Aalen: Scientia, 1964).

6. BRACH, M. "Spinoza, Herr von Hartmann um der Antisemitismus" (Spinoza, o Senhor de Hartmann e o Antisemitismo). In: Allgemeine Zeitung des Judentums 54 (1890).

7. DUNIN-BORKOWSKI, S. Spinoza. Münster: Aschendorff, 1933-1936, 4 volumes, somando no total mais de 2000 páginas.

8. FISCHER, K. Spinozas Leben, Werk und Lehre, (Vida, obra e doutrina de Espinosa) $6^{\mathrm{a}}$ Ed., Heidelberg: Winter, 1946. [Fischer, Geschichte der neuern Philosophie (História da filosofia moderna)].

9. FRANZ, E. Deutsche Klassik und Reformation ( $O$ Classicismo alemão $e$ Reforma), Halle/Saale: Niemeyer, 1937. (Deutsche Vierteljahrsschrift für Literaturawissenchaft und Geistergeschichte, Buchreihe; 22.) (Publicação trimestral alemã sobre Ciência da Literatura e História dos Espíritos).

10. GLASENAPP, G. "Spielarten jüdischer Identitäsbestimmung im frühen 19. Jahrhundert. Berthold Auerbachs Spinoza-Roman", (A variedade de determinações de identidade na primeira metade do século XIX. O Spinoza-Roman de Berthold Auerbach), in: Spinoza in der europäischen Geistesgeschichte. (Espinosa na história do espírito europeu). H. Delf; J. H. Choeps; Ma. Walther (Hg.) Berlin: Hentrich, 1994 (Studien zur Geistesgeschichte; 16): 289-304.

11. GLOCKNER, H. Vom wesen der deutschen Philosophie (Da essência da filosofia alemã). Stuttgart; Berlin: Kohlhammer, 1941.

12. GRAU , W. Die Judenfrage als Aufgabe der neuen Geschichtsforschung (A questão judaica enquanto tarefa da nova pesquisa histórica), Hamburg: Hanseatische Verlagsanstalt, 29 p.) [1920, como artigo na revista Deutsches Volktum (Povo alemão)]

13. GRUNSKY,H.A. “Baruch Spinoza”. In: Forschungen zur Judenfrage(Investigações sobre a questão judaica), Vol 2 (Atas da Segunda Divisão da Divisão de Pesquisa acerca da Questão Judaica do Instituto do Reich para a História da Nova Alemanha, de 12 a 14 de maio de 1937). Hamburg, 1937, p.88-117.

14. HARTMANN, E. Judentum in Gegenwart und Zukunft (Judaísmo no presente e no futuro). Leipzig; Berlin: Friedrich, 1885

15. HAUSER, O. Spinoza. Roman, Stuttgart: Bonz, 1907 (2 $2^{\mathrm{a}}$ edição: 1907; $3^{\mathrm{a}}$ e a $4^{\mathrm{a}}$ edições: 1924).

16. HELMES,G. Spinoza in der schönen Literatur: Bilder aus der Zeit zwischen Vormärz und Weimarer Republik. (Espinosa na bela literatura: retratos do período entre Vormärz e a República de Weimar). In: Studia Spinozana, 5 (1989) (Spinoza and Literature), p.119-149.

17. HERDER, J. G. Gott. Einige Gespräche über Spinoza's System (Deus. Alguns diálogos acerca do sistema de Espinosa). Herders Werke. Heinrich Dünzer 
(Ed.) Berlin 1994.

18. HÖLTERS, H. Der spinozistische Gottesbegriff bei M. Mendelssohn und F. H. Jacobi und der Gottesbegriff bei Spinoza (O conceito espinosista de Deus em M. Mendelssohn e F. H. Jacobi e o conceito de Deus em Espinosa. Emsdetten: Lechte, 1938. (Universitäts-Archiv; 97.)

19. KATZ, J. "Spinoza und die Utopie einer totalen Assimilation der Juden”. (Espinosa e a utopia de uma total assimilação dos judeus). In: Id., Zur Assimilation und Emanzipation der Juden. Ausgeeewählte Schriften. (Sobre a assimilação e emancipação dos judeus. Textos escolhidos). Darmstadt: Wissenschaftliche Buchgesellschaft, 1982, p.199-209.

20. KILCHER, A. B. "Spinoza als Apokalyptiker. Theologisch-politische Konstellationen in den Spinoza-Romanen der Moderne" (Spinoza como apocalíptico. Constelações teológico-políticas nos romances dos modernos sobre Spinoza), in: Ein neuer Blick auf die Welt. Spinoza in Literatur, Kunst und Ästhetik. (Um novo olhar sobre o mundo. Spinoza na Literatura, na Arte e na Estética). Editado por M. Bollacher, T. Kisser e M. Walther. Würzbug: Königshausen \& Neumann, 2010 (Schriftenreihe der SpinozaGesellschaft; 14) (p.83-101).

21. KOLBENHEYER, E. G. - Amor Dei. Ein Spinoza-Roman, München: Müller, 1908.

22. LAGNY, A. "Spinoza personnage de roman chez B. Auerbach (Spinoza. Ein Denkerleben) et E. G. Kolbenheyer (Amor Dei)". In: Spinoza au XXe siècle. Olivier Bloch (dir.). Paris: Presses Universitaires de France, 1993 (Philosophie d'aujourd'hui).

23. LANGBEHNS, J. Rembrandt als Erzieher (Rembrandt como educador) Leipzig: Hirschfeld, 1890 (citado de acordo com a 12 ${ }^{\mathrm{a}}$ Edição do mesmo ano).

24. ROSENBERG, A. Die Spur des Juden im Wandel der Zeiten (O rastro do judeu no decorrer dos tempos), München 1920[depois seguem mais quatro edições, dentre as quais, três na Editora Central da NSDAP e, por fim, na 34.-53. Tsd. München 1943].

25. SCHEWE, M. 'Langbehn, August Julius'. In: Biographisch-Bibliographisches Kirchenlexikon, Vol. IV (1992).

26. SCHROER ."Das Judentum in der Rechtswissenschaft" ("O judaísmo na ciência do direito"), Die deutsche Rechtswissenschaft im Kampf gegen den jüdischen Geist. (A ciência do direito alemão em luta contra o espírito judeu). Berlim: Deutscher Rechts-Verlag, sem data, p.18-22.

27. SELCHOW, B.Die Not unseres Rechts. Eine Wegschau. (A miséria do nosso Direito. Vista de um caminho). Leipzig 1932.

28. SENN, M. "Rassistische und antisemitische Elemente im Rechtdenken Johann Caspar Bluntschlis". (Elementos racistas e antisemitas no pensamento sobre o direito de Johann Caspar Bluntschli). In: Zeitschrift der SavignyStiftung für Rechtsgeschichte, Germanisctische Abteilung 110 (1993)

29. SPINOZA, Lebensbeschreibungen und Dokumente. Nova edição ampliada com comentário editado por Manfred Walther. Tradução da Lebensbeschr. de Carl Gebhardt. Hamburg: Meiner, 1988 (Philosophische Bibliothek; 96b), Dokument 53 (com comentários).

30. STRAUSS, L."Anleitung zum Studium von Spinozas theologisch-politischem Traktat” (Introdução ao estudo do Tratado teológico-político de Spinoza). In: Texte zur Geschichte des Spinozismus. (Textos sobre a história do espinosismo). Norbert Altwicker (Ed.). Darmstadt: Wissenchaftliche Buchgesellschaft, 197, p.300-361. (Apareceu primeiro como: How to Study Spinoza's Theological-Political Treatise. In: Proceedings of the American Academy for Jewish Studies XVIII (1948), p. 69-131. Renovado em: Strauss, Persecution and the Art of Writing. New York 1952, p. 142201.)

31. WALTHER, M. Das Leben Spinozas: Eine Bibliographie. (A vida de Spinoza: uma bibliografia). Hannover: Uni-Verlag Witte 1996.

32. _. Spinoza in Literature in Studia Spinozana 6 (1986), p.377-380.

33. __ Spinozas Philosophie der Freiheit eine "jüdische Philosophie”? (A filosofia spinozana da liberdade, uma "filosofia judaica"?) In: Edith Stein Jahrbuch 3 (1997) (Das Judentum).

34. Spinoza und das Problem einer jüdischen Phliosophie. (Spinoza e o problema de uma filosofia judaica). In: A atualidade da tradição judaica. Ed. por Werner Stegmeier. Frankfurt am Main: Suhrkamp, 2000.

35. W_ Was Spinoza a "Jewish philosopher"? Spinoza in the struggle for a modern Jewish cultural identity in Germany. A meta-reflection, in: Studia Spinozana 13 (1997, publicado em 2003) (Spinoza and Jewish Identity).

36. WENZEL, A. Die Weltanschauung Spinozas (A visão de mundo de Espinosa). Vol.1: Spinozas Lehre von Gott, von der menschlichen Erkenntnis und von dem Wesen der Dinge. (A doutrina espinosana de Deus, do conhecimento 
humano e da essência das coisas). Leipzig: Engelmann, 1907 (ND Aalen: Scientia, 1883)

37. WERTHEIM, D. "The Simbolic Meaning of a Presumed Relationship. Rembrandt and Spinoza in German Literature, 1890-1934”. In: Ein neuer Blick auf die Welt. Spinoza in Literatur, Kunst und Ästhetik. M. Bollacher; T. Kisser u. M. Walther (Hg.). Würzburg: Königshausen \& Neumann, 2010 (Schriftenreihe der Spinoza-Gesellschaft; 14), p.73-81.

38.WOLFF ,H. M. Spinozas Ethic. Eine kritische Einführung (A Ética de Espinosa. Uma introdução crítica), Francke in Bern:1958.

39. WUNDT, W.- Die Nationen und ihre Philosophie. Ein Kapitel zum Weltkrieg (As nações e suas filosofias. Um pretexto para a guerra mundial), Leipzig: Kröner, 1915. Citado segundo a Edição de 1944 (!).

40. . Über die Nationen und ihre Philosophie (Sobre as nações e sua filosofia), que havia aparecido em oito edições antes de 1933, é assistida com mais edições em 1935, 1941 e 1944

\section{NOTAS}

1. "No estrito domínio da história do espírito, a mediação judaica de Aristóteles no Ocidente e o problema-Spinoza na história europeia poderiam ser esclarecidos sob o ponto de vista do judaísmo" (Grau, 12, p.26), lemos no escrito programático Die Judenfrage als Aufgabe der neuen Geschichtsforschung (A questão judaica enquanto tarefa da nova pesquisa histórica) de Wilhelm Grau, que aparecera, já em 1920, como artigo na revista Deutsches Volktum (Povo alemão), e que lista detalhadamente quais temas deveriam ser trabalhados "no ponto de corte que separa as esferas de vida alemã e judaica" (Grau 12, p.9).

2. Uma visão geral, de maneira alguma completa, das publicações desses gêneros diversos que apareceram em alemão, de 1782 a 1935 (e dali para frente), é apresentada por Manfred Walther, Das Leben Spinozas: Eine Bibliographie. (A vida de Spinoza: uma bibliografia) (Walther 31, p.83-86); a mesma também na Studia Spinozana 6 (1986) (Spinoza in Literature) (Walther 32, p. 377-380).

Outros mais títulos correspondentes ao assunto, encontramos na Bibliografia-Online www.spinoza-bibliografie.de, quando, sob o ícone "Literatursorte" entramos com a expressão de busca "Lyrik, Prosa, Filme, Kunst", no período "1875-1932", e selecionamos a língua "deutsch".

3. Autores de procedência judaica, exceto um nome, não são levados em consideração, uma vez que o(s) seu(s) retrato(s) de Spinoza, na medida em que se mostram como obstáculos a serem superados na luta contra Spinoza durante o período NS, não suscitam interesse.

A discussão "intrajudaica" em torno de/com Spinoza aparece nos meus trabalhos seguintes:

a. Spinozas Philosophie der Freiheit eine "jüdische Philosophie"? (A filosofia spinozana da liberdade, uma "filosofia judaica"?) (Walther 33, p.99-113, seções 3.23.3, p.111-121).

b. Spinoza und das Problem einer jüdischen Phliosophie. (Spinoza e o problema de uma filosofia judaica).(Walther 34, p. 281-330).

c. Was Spinoza a "Jewish philosopher"? Spinoza in the struggle for a modern Jewish cultural identity in Germany. A meta-reflection, (Walther 35,p. 207-237, Seção III. The patterns of locating Spinoza in relation to Jewishness: The "Jewish" discourse, p. 211-218; Seção VI, p. 222-226).

Certas passagens de um ou outro desses trabalhos foram usadas no presente texto.

4. O texto pode ser encontrado em tradução alemã, além de noutros, no: Baruch de Spinoza, Lebensbeschreibungen und Dokumente. Nova edição ampliada com comentário editado por Manfred Walther. (Spinoza 29).

5. Ela vem destacada, p. e., em Moritz Brach, Spinoza, Herr von Hartmann um der Antisemitismus (Spinoza, o Senhor de Hartmann e o Antisemitismo). (Brach 6, p. 566-569).

6. Para isso e para a biografia de Kolbenheyer antes, durante e depois do período NS, confira Lagny 22, p.459-482 (470-475, 478).

Em relação a Kolbenheyer, veja também Kilcher 20, p. 84-85, 87, 88), e Wertheim 37, p. 77.

7. Auerbach 1. A partir da $2^{\text {a }}$ Ed., intensamente reformulada, Auerbach 2. Submetida a novos estudos na edição estereotipada Mannheim: Bassermann e Mathy, 1854, muitas vezes reimpressa. Eu tenho à disposição várias reimpressões da $7^{\mathrm{a}}$ edição.

Sobre o Romance-Spinoza de Auerbach, confira também:

Günter Helmes 16,p.119-149 (123-129); Lagny 22 ,p. 461-470; Glasenapp 10 p.289-304. Uma breve caracterização do retrato de Espinosa e, respectivamente, do auto-retrato de Auerbach também nos é dada por Katz 19, p.200-201.

8. Esse escrito, publicado também ao mesmo tempo numa versão de livros de bolso, é muitas vezes reeditado; em 1929 já aparece a $8^{\text {a }}$ edição.

9. No que diz respeito ao retrato de Spinoza feito por Langbehn, veja também 
Wertheim 37, p. 74-76.

10. Relativamente a esse "judaísmo originariamente aristocrático", torna-se manifesto ao mesmo tempo, também, em Langbehn, até que nível despencara o novo judaísmo que vivia na Alemanha e arrastara consigo a cultura alemã.

11. Somente em 1944 aparece com Fritzsche em Berlim uma nova Edição, preparada por Gerhard Krüger, na qual todas as referências positivas a Espinosa são removidas. 12. 1937: Prêmio Goethe da cidade de Frankfurt am Main; 1938: Escudo da Águia do Império Alemão; 1941: Plaqueta-Kant da cidade de Königsberg; 1944: PrêmioGrillparzer.

13. Ofício da Câmara Oficial do Reich para esclarecimento popular e propaganda, dirigido à Livraria Universitária Carl Winters, de 27.1.44.

A passagem incriminada começa da seguinte maneira: "Jamais ao longo da Idade Média o judaísmo desenvolvera um ramo tão imponente do povo decaído e espalhado pelo mundo, um florescimento tão elevado da cultura e da prosperidade, da ciência e do trabalho artístico, quanto na Espanha". (Fischer 8, p.2.)

14. A sua contribuição para o debate está publicada no $1^{\circ}$ dos, ao todo, 9 cadernos da Série abrangente sobre "Das Judentum in der Rechtswissenschaft" ("O judaísmo na ciência do direito"), que traz o título: Die deutsche Rechtswissenschaft im Kampf gegen den jüdischen Geist. (A ciência do direito alemão em luta contra o espírito judeu). O caderno também contempla a abertura e a conferência de encerramento de Carl Schmitt.

15. Isso não foi algo que "judeus alegaram”, mas o próprio Goethe o falou acerca do efeito da sua leitura da Ética de Spinoza!

16. Isso soa fortemente a uma retomada, p. ex., da crítica que Eduard von Hartmann formulou contra Espinosa (veja acima, na seção 2.1).

17. Sobre a diferença fundamental entre Espinosa e Nietzsche, veja lá na p. 95 , anotação 2, sobre o caráter judaico da doutrina da multidão de Cantor e a física de Einstein, p.103, anotação 1, e p.107.

18. Primeiro em München 1920; depois seguem mais quatro edições, dentre as quais, três na Editora Central da NSDAP e, por fim, na 34.-53. Tsd. München 1943.

19. Somente a Spinozas Ethic. Eine kritische Einführung (A Ética de Espinosa. Uma introdução crítica) de Hans M. Wolff aparece já em 1958, em Francke in Bern. Wolff, jurista promovido com fortes inclinações para literatura e filosofia; após o seu segundo doutorado em Germanística, leciona na Brown University, em Providence, na Ilha de Rhode, e não retorna mais para a Alemanha. Ele morre em 1958. Ver Karl S. Guthke, Hans M. Wolff - em vez do Monatshefte necrológico 51,4 (1959): 193-196.

\section{EXPERIMENTAÇÃO POLÍTICA DA AMIZADE A PARTIR DA TEORIA DOS AFETOS DE ESPINOSA}

Lívia Godinho Nery Gomes*

Nelson da Silva Júnior*

Resumo: A amizade é concebida neste estudo como tendo um sentido político, pois uma condição necessária do exercício político é aquela de considerar a opinião do outro. Em seu sentido político, a amizade favorece o questionamento de pontos de vista fixos e a irrupção de ações inovadoras. A experimentação política da amizade constitui uma relação agonística, de abertura ao outro na qual os corpos estão dispostos a afetar e serem afetados, implicados em contribuir com o aumento da capacidade de reflexão e ação do amigo. Este artigo tem como objetivo discutir a experimentação política da amizade a partir da teoria dos afetos de Baruch Espinosa: o corpo é essencialmente relacional e é na relação com seus outros, na maneira como afeta e é afetado por eles que se dá a condição de possibilidade da resistência à tristeza e afirmação da alegria compreendida como aumento da potência de pensar e agir.

Palavras-chave: amizade, experimentação, política, afetos, Espinosa

A amizade compreendida em sua qualidade política, ou seja, enquanto vínculo agonístico que permite transformações no registro da subjetividade, diz respeito à potência dos encontros e às forças mobilizadas por estes. Neste sentido, a questão da experimentação política da amizade

* Professora Adjunta do departamento de Psicologia da Universidade Federal de Sergipe. O presente artigo refere-se a uma parte da tese de doutorado, intitulada "Implicações políticas das relações de amizades mediadas pela internet”. A pesquisa foi realizada com apoio financeiro da Fundação de Amparo à Pesquisa do Estado de São Paulo (FAPESP).

** Professor Livre Docente do Departamento de Psicologia Social e do Trabalho do Instituto de Psicologia da Universidade de São Paulo. 